\title{
Sexual Dimorphism of Brown Adipose Tissue Function
}

\section{Authors}

Lindsay J Robinson ${ }^{1}$, MB ChB, James Law ${ }^{1}$, MBBS, Valerie Astle ${ }^{1}$, MBBS, Marta Gutiérrez García ${ }^{4}$, Shalini Ohja $^{5}$ MBBS, PhD, Michael E Symonds ${ }^{1,2}$, PhD, Nicola Pitchford ${ }^{3}$, D.Phil, Helen Budge ${ }^{1}$, BM BCh, PhD

${ }^{1}$ Division of Child Health, Obstetrics and Gynaecology, ${ }^{2}$ Nottingham Digestive Disease Centre and Biomedical Research Centre, ${ }^{5}$ Division of Medical Sciences and Graduate Entry Medicine, School of Medicine, ${ }^{3}$ School of Psychology, University of Nottingham, University of Nottingham, Nottingham, UK, NG7 2UH; ${ }^{4}$ University of Grenada Medical School, Grenada, Spain

Short Title-Sexual dimorphism of brown fat function in children

Corresponding author - Professor Michael E Symonds Division of Child Health, Obstetrics and Gynaecology, School of Medicine, University Hospital, University of Nottingham, Nottingham, NG7 2UH, United Kingdom

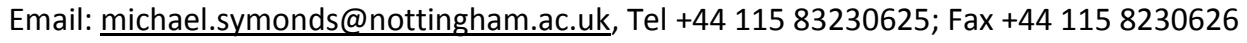




\section{Author contributions}

N Pitchford (NP) and H Budge (HB) conceived and designed the study and attained funding. LRobinson (LR) refined the study design, led data interpretation and drafted the manuscript. Data analysis was undertaken by Jaw (H), VAstle, LRobinson and M García. HB, JL, NP, SO, LR, and MES revised it critically for important intellectual content. All authors approved the final version of the manuscript and agree to be accountable for all aspects of the work.

\section{Funding Sources}

Funded by the University of Nottingham Schools of Psychology and Medicine. The authors declare no conflicts of interest.

Conflict of interest

None declared. 
Abbreviations and acronyms

BAT - Brown adipose tissue

SCR - Supraclavicular region

Comment [BW1]: Copyeditor: Please expand "SCR" as

"Supraclavicular region" throughout

$\mathrm{T}_{\mathrm{SCR}}$ - Temperature of the supraclavicular region

$\Delta T_{S C R}-$ Change in supraclavicular temperature in response to cold-exposure

UCP1 - Uncoupling protein one

PET-CT - Positron emission-computed tomography

$T_{m p}-$ Temperature of the anterior mandibular protuberance

FSH - Follicle-stimulating hormone

IRT - Infrared thermography

$\mathrm{BMI}$ - Body mass index 


\section{Abstract}

\section{Objective}

To determine whether BAT activity in school-age children differs between the sexes and to explore the impact of dietary intake, sedentary behaviourbehavior, and "_picky/fussy eating."'-

\section{Study design}

Thirty six $\in$ Children aged $8.5-11.8$ years of age $(n=36)$ underwent infrared thermography (IRT) to determine the temperature of the skin overlying the main superficial BAT depot in the supraclavicular region (SCR) prior to, and following, 5 minutes' mild cold-exposure (single-hand immersion in cool tap water c. $20^{\circ} \mathrm{C}$ ). Relationships between SCR temperature $\left(T_{S C R}\right)$ and parental reports of food consumption, eating behaviour and inactivity were explored.

\section{Results}

$T_{S C R}$ was higher in boys ( $\left.n=16\right)$ at baseline, and following cold-exposure. Boys displayed a greater thermogenic response to cold. Strong negative correlations were observed between $\mathrm{T}_{\mathrm{SCR}}$ and BMI centile, and differences in $\mathrm{T}_{\mathrm{SCR}}$ between girls and boys persisted after adjustment for BMI centile. A negative linear relationship was observed between protein and vegetable intake and $\mathrm{T}_{\mathrm{SCR}}$ in girls only, but did not persist after adjustment for multiple comparisons. There was no difference in adjusted $\mathrm{T}_{\mathrm{SCR}}$ between active or inactive children, or picky/non-picky eaters.

\section{Conclusion}

These findings indicate sexual dimorphism in BAT thermogenic activity and a sex-specific impact of diet. Future studies should aim to quantify the contribution of BAT to childhood energy expenditure, energy imbalance, and any role in the origins of childhood obesity. 
Introduction

Globally, over 124 million school-age children are now classified as overweight or obese ${ }^{1}$ and, as a consequence, are at risk of significant cardio-metabolic disease in adulthood ${ }_{2}^{2,3}$, The individual $^{-}$ components of childhood energy balance are poorly understood, and the impact of brown adipose tissue (BAT) on energy expenditure, has yet to be quantified.

BAT persists outside the neonatal period into childhood and beyond. Increasing evidence suggests that this highly metabolic, thermogenic tissue contributes to energy expenditure by oxidising lipids and glucose ${ }^{4-7}$. This is achieved by the dissipation of chemical energy as heat through the action of mitochondrial uncoupling protein (UCP)1. Histological evidence of BAT has been demonstrated in children in the neck, upper thorax, mediastinum ${ }^{8,9}$, and in the adipose tissue surrounding the heart ${ }^{10}$ and kidneys ${ }^{8,11}$ as well as subcutaneously $^{11}$. It is estimated that just $63 \mathrm{~g}$ of adult BAT could combust the energy equivalent of $4.1 \mathrm{~kg}$ of white adipose tissue over the course of a year ${ }^{12}$. As the prevalence and activity of BAT are higher throughout infancy ${ }^{9,13}$ and childhood ${ }^{14}$, the relative contribution of BAT to bio-energetic metabolism may be even greater in infants and children than in adulthood.

Although associations between dietary intake and sedentary behaviours, such as TV viewing, on white

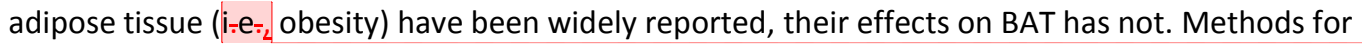
measurement of supraclavicular skin temperature using thermal imaging present an ethically acceptable, non-invasive, repeatable method for BAT assessment in children and have been repeatedly shown to reflect measurements of BAT activity as assessed on positron emission tomography/computed tomography $(\text { PET-CT })^{15-17}$

Sexual dimorphism in both BAT mass and its activity has been comprehensively reviewed in adults ${ }^{18,19}$ and, despite similar distribution of depots throughout the body, pre-menopausal women appear to have more BAT than men ${ }^{20,21}$ implicating a role for hormonal regulation. Data in infants and children are less clear ${ }^{11,}$ 14, 22-27. Gilsanz et al report a higher BAT mass, increased BAT activity and more rapid increase in BAT during the pubertal growth spurt in boys, as compared towith girls ${ }^{14}$. Although glucose is utilised during BAT

Comment [MM4]: Copyeditor: Please format ie, etc, vs, eg per Journal style throughout (no periods)
Comment [MM3]: Copyeditor: Please format citations per Journal style throughout 
thermogenesis, the primary substrates for brown adipocytes at the cellular level are fatty acids. Functional assessment of BAT beyond that of glucose uptake is integral to understanding how BAT may be regulated and its contribution to energy expenditure in early life.

Given the potential importance of BAT activity in metabolic health, our aim was to determine whether the sexual dimorphism observed in adults exists between girls and boys at baseline and in response to a brief mild cold stimulus ${ }^{28,29}$ when IRT of supraclavicular skin temperature is utilised as a measure of BAT thermogenic activity. In addition, as diet and habitual physical activity influence metabolic health, we sought to identify whether parental reports of dietary intake, picky eating behaviour, and TV viewing were associated with differences in BAT activity in a sex-specific manner.

\section{Methods}

This study was approved by the University of Nottingham's School of Medicine Ethics Committee (E10012013 SCS ACH TREAT). Participants were recruited from two Nottingham City schools over a period of 3 weeks, and data collection was undertaken between April and June 2013. There were no specific eligibility criteria other than the requirement for parental written consent and receipt of children's verbal consent for anthropometry and imaging. Parents/guardians gave informed written consent for participation in this study, and all children gave additional verbal assent. Thirty-six children were imaged under free-living conditions within a primary school environment.

Infrared thermography of the neck and upper thorax was undertaken as previously described ${ }^{28}$. In brief, the reflective temperature, ambient room temperature and humidity were measured prior to each imaging session and entered into the thermal camera according to manufacturer's instructions. Supraclavicular $(\mathrm{SCR})$ temperature $\left(\mathrm{T}_{\mathrm{SCR}}\right)$ is also related to ambient temperature ${ }^{28}$, and ambient room temperatures were stable during the study (Table $\| 1$ ). Each child sat $0.8 \mathrm{~m}$ away from the thermal camera (FLIR B425FLIR Systems AB, Danderyd, Sweden) for 5 minutes wearing a sleeveless cotton vest. BAT in children responds to very mild cold stimulation ${ }^{28-30}$ and participants next immersed their left hand in cool tap water (c. $20^{\circ} \mathrm{C}$ ) for 5 minutes, producing a similar decrease in hand temperature in girls and boys (Table 1). Images were

Comment [MM5]: Copyeditor: Please format Table numbers per Journal style throughout (Roman numerals) 
taken at intervals throughout the study with comparable subject positioning. Thermograms obtained 1 minute prior to hand immersion, and 5 minutes post-hand immersion, were analysed to calculate $\mathrm{T}_{\mathrm{SCR}}$. Values were defined as baseline $T_{S C R}$ and cold-exposed $T_{S C R}$ respectively, and the thermogenic response to cold as $\Delta \mathrm{T}_{\mathrm{SCR}}$ (calculated as cold-exposed $\mathrm{T}_{\mathrm{SCR}}$ minus baseline $\mathrm{T}_{\mathrm{SCR}}$ ). For the purposes of image analysis, the supraclavicular region was defined as the region of skin visible between the acromioclavicular joint, sternal notch and contour of the shoulder. Only thermograms where both left and right SCRs were completely exposed and unobstructed by clothing or hair, and where clavicles were positioned perpendicular to the camera lens, were regarded as acceptable for analysis.

The radiometric data obtained from thermograms were converted to temperature data within MATLAB (2017b, Mathworks, Natick, MA, USA) using a script adapted from Tattersall (2015). The thermal image was displayed on a graphical user interface, allowing identification of 5 points representing the apices of the SCR as defined above. $T_{S C R}$ was calculated as the $95^{\text {th }}$ percentile temperature value of the SCR of interest ${ }^{15}$, 29, 31 .

To determine baseline temperature of the skin not overlying BAT, a region away from the proximity of supraclavicular BAT visible in all children's thermograms was chosen as a comparator. This anatomical region, the centre of the anterior mandibular protuberance, was identified visually using FLIR's proprietary software, ResearchIR version 4 (FLIR Systems AB, Danderyd, Sweden). The mean temperature value of an 86-pixel area ellipse $\left(T_{\mathrm{mp}}\right)$ was calculated pre- and post-cold exposure (using the same thermograms as for the calculation of $\left.\mathrm{T}_{S C R}\right)$. To confirm, and quantify, the degree of hand cooling, the temperature of the left hand prior to, and immediately after, cooling was calculated for each subject using the mean value of an individualised maximally-sized ellipse fitted to the anatomical area bound by the metacarpophalangeal joints and radial-ulnar styloid processes on the dorsum of the hand. Nine of the 36 children analysed for this study did not have thermograms of the left hand both prior to, and following, hand immersion. $T_{\mathrm{mp}}$ and hand temperature were calculated using the standard ellipse region-of-interest tool in ResearcherIR version 4 (FLIR Systems AB, Danderyd, Sweden). 
The parents of each child completed questionnaires regarding their child's food intake, and were asked to rate their child's frequency of consumption of 151 foods (adapted from Wardle et al ${ }^{32}$ ) from 1 to 8 ( 1 'more than once a day' to 7 'less than once a month' and where 8 represented 'never' eaten). Responses were grouped into 7 standard food categories as described previously $y^{33}$ and summed to create a score for each food group for each child. Each food group consisted of between 9 and 20 items.

Where consumption of a food was rated as 'never' in more than $25 \%$ of children, that food was excluded from grouped analysis ${ }^{32}$. Remaining foods were grouped into the following categories: i) carbohydrate; ii) dairy; iii) fruit; iv) protein; v) savoury; vi) sweet and vii) vegetable. Cronbach alpha was calculated for each group as a measure of the internal consistency of the scale. Reliability was acceptable (Cronbach's alpha > $0.7^{34}$ ) for all groups except dairy (0.54) for the food consumption questionnaires. 'Food consumption score', as a sum for each food group, was calculated for each child and compared to-with indices of supraclavicular temperature (i.e. baseline $T_{S C R}$, cold-exposed $T_{S C R}$ and $\Delta T_{S C R}$ ) derived from thermograms as described above.

To identify children with fussy eating behaviour, parents were asked if they would classify their child as a "picky eater". Parents were also asked to estimate their child's duration of TV exposure per day to the nearest half an hour. Those children reported as watching $\geq 2$ hours a day were classed as sedentary, and those watching $<2$ hours TV a day as active.

To ensure responses were not contaminated by socially-desirable responding, parents also completed a short form of the Marlowe-Crowne Social Desirability Scale (MCSDS) ${ }^{35}$. Analysis of the MCSDS identified that food consumption scores were not contaminated by socially desirable responding. However, MCSDS scores were significantly correlated with the estimated number of hours of TV watched.

Height was measured to the nearest $0.1 \mathrm{~cm}$ using a stadiometer (Leicester height measure; Child Growth Foundation, Sutton Coldfield, United Kingdom), and weight to the nearest $0.1 \mathrm{~kg}$ using a standard, calibrated weighing scale. BMI centile was calculated to adjust for sex and age using the National Health 
Service Choices BMI calculator ${ }^{36}$. Height, weight and BMI centile for the children in this study are summarised in Table 1.

\section{Statistical analysess}

Data were analysed using SPSS V.24 (IBM, Armonk, New York). Data are meanıstandard error and normally distributed (as assessed by the Shapiro-Wilk normality test) unless stated otherwise. Comparisons between left and right $\mathrm{T}_{\mathrm{SCR}}$ were performed using the paired t-test. Percentages were compared using the chisquared test. Pearson's product-moment correlation coefficients were calculated to determine the correlation between $T_{S C R}$ and food exposure scores and $T_{S C R}$ and BMI centile. A two $\underline{2}$-way mixed ANOVA was conducted to examine the effects of sex and cold-exposure on $\mathrm{T}_{\mathrm{SCR}}$. Post-hoc comparisons were undertaken using the t-test. ANCOVA was performed to determine the effect of sex and cold-exposure on $\mathrm{T}_{\text {SCR }}$ after controlling for BMI centile. Two-way ANCOVA was conducted to examine the effects of sex and sedentary behaviour, and sex and picky eating behaviour, on $\mathrm{T}_{\mathrm{SCR}}$ after controlling for BMI centile.

A sample size of 30 (15 boys and 15 girls) was calculated to detect a $25 \%$ difference in the supraclavicular skin temperature (i.e. $\Delta \mathrm{T}_{\mathrm{SCR}}$ ) in response to cold-exposure, based on previously published data from healthy children of comparative age ${ }^{28}$ (i.e. right $\Delta T_{S C R} 0.28 \pm 0.064^{\circ} \mathrm{C}$ (mean $\left.\left.\pm S D\right), \beta=0.2, \alpha=0.05\right)$.

$P$ values of $<0.05$ ( 2 tailed) were considered statistically significant. To account for multiple testing during calculation of Pearson's correlation coefficient, the false discovery rate (FDR) was controlled using the corrected method of Benjamini and Yekutieli ${ }^{37}$ with the desired FDR of 5\%.|

\section{Results}

The skin temperature overlying supraclavicular BAT was higher in boys at baseline, following coldexposure, and there was a greater change in temperature response to cold-exposure which was significant in boys but not girls (Figure-1). Consistent with this, sex had a statistically significant effect on the $T_{S C R}$ response to cold-exposure (right $\mathrm{T}_{\mathrm{SCR}}: F(1,34)=6.37, \mathrm{p}=0.016$, partial $\eta^{2}=0.16$; left $\mathrm{T}_{\mathrm{SCR}} F(1,34)=6.41, \mathrm{p}^{P}=$ Q.016, partial $\left.\eta^{2}=0.16\right)$. 
Since-Because a significant negative linear relationship was observed between $\mathrm{T}_{\mathrm{SCR}}$ and BMI centile ( $r=$ 0.71 to $-0.43, p<0.01$ ), even after correction for multiple comparisons (data not shown).

Adjusted cold-exposed $\mathrm{T}_{S C R}$ was statistically higher in boys than girls (right $\mathrm{T}_{S C R}$ mean difference: $0.41^{\circ} \mathrm{C}$ $\left(95 \% \mathrm{Cl} 0.14\right.$ to $\left.0.68^{\circ} \mathrm{C}\right)$; left $\mathrm{T}_{\mathrm{SCR}}$ mean difference: $0.41^{\circ} \mathrm{C}\left(95 \% \mathrm{Cl} 0.12\right.$ to $\left.\left.0.70^{\circ} \mathrm{C}\right)\right)$ but the similar trend in baseline $\mathrm{T}_{\mathrm{SCR}}$ did not maintain statistical significance (right $\mathrm{T}_{\mathrm{SCR}}: F(1,33)=3.48, \mathrm{p}=0.07$, partial $\eta^{2}=0.10$; left $\mathrm{T}_{\mathrm{SCR}}: F(1,33)=3.46, \mathrm{p}=0.07$, partial $\left.\eta^{2}=0.10\right)$. However, thermogenic response to cold-exposure $\left(\Delta \mathrm{T}_{\mathrm{SCR}}\right)$ remained greater in boys (right $\mathrm{T}_{\mathrm{SCR}}$ mean difference: $0.14^{\circ} \mathrm{C}\left(95 \% \mathrm{Cl} 0.02\right.$ to $\left.0.26^{\circ} \mathrm{C}\right)$; left $\Delta \mathrm{T}_{\mathrm{SCR}}$ mean difference: $0.14^{\circ} \mathrm{C}\left(95 \% \mathrm{Cl} 0.02\right.$ to $\left.\left.0.25^{\circ} \mathrm{C}\right)\right)$. The adjusted means for $\mathrm{T}_{\mathrm{SCR}}$ at baseline, following coldexposure and for $\Delta T_{S C R}$, are summarised in Table 2 .

A significant negative linear relationship between $\mathrm{T}_{\mathrm{SCR}}$ and parental report of vegetable and protein consumption was observed in girls. However, these relationships were no longer statistically significant following adjustment for multiple testing in our study sample. There were no associations between $\mathrm{T}_{\text {SCR }}$ and food consumption in any category in boys (Table 3) and no difference in vegetable and protein consumption scores between girls and boys (Table 1 ).

Sixty-one percent of children were reported to watch $\geq 2$ hours of television per day, but there was no significant difference between boys and girls (Table 1). There was no effect of sex and sedentary behaviour (classified as $\geq 2 \mathrm{~h}$ television per day) on $\mathrm{T}_{\mathrm{SCR}}$ after controlling for the effect of BMI centile and no statistically significant 2 -way interaction between sex and sedentary behaviour, while controlling for BMI centile (Table 4; available at www.jpeds.com).

Therefore, an analysis of the main effects of sedentary behaviour and sex was performed. There was no statistically significant difference in unweighted marginal adjusted means for the main effect of sedentary behaviour on left, or right, $\mathrm{T}_{\mathrm{SCR}}$ at baseline, or following cold-exposure (Baseline: right $\mathrm{T}_{\mathrm{SCR}}$ mean difference: $-0.25^{\circ} \mathrm{C}\left(95 \% \mathrm{Cl}-0.54\right.$ to $\left.0.05^{\circ} \mathrm{C}\right), \mathrm{p}=0.09$; left $\mathrm{T}_{\mathrm{SCR}}$ mean difference: $-0.12^{\circ} \mathrm{C}(95 \% \mathrm{Cl}-0.43$ to $\left.0.19^{\circ} \mathrm{C}\right), p=0.44$; Following cold-exposure: right $\mathrm{T}_{S C R}$ mean difference: $-0.18^{\circ} \mathrm{C}\left(95 \% \mathrm{Cl}-0.46\right.$ to $\left.0.10^{\circ} \mathrm{C}\right)$, $\mathrm{p}=0.19$; left $\mathrm{T}_{\mathrm{SCR}}$ mean difference: $-0.10^{\circ} \mathrm{C}\left(95 \% \mathrm{Cl}-0.39\right.$ to $\left.\left.0.22^{\circ} \mathrm{C}\right), \mathrm{p}=0.58\right)$. 
Fifty-three percent of children were reported to be picky eaters by their parents. There was no significant difference between the eating behaviour of girls or boys (Table 1). A 2 -way ANCOVA was conducted to examine the effects of sex and picky eating behaviour on $T_{S C R}$, while adjusting for the effect of BMI centile and there was no statistically significant two-way interaction between sex and picky eating behaviour while controlling for BMI centile (Table 5; available at www.jpeds.com).

Therefore, an analysis of the main effects of picky eating behaviour and sex was performed. The main effect of eating behaviour showed no statistically significant difference in unweighted marginal adjusted means of the left or right $\mathrm{T}_{\mathrm{SCR}}$ at baseline or following cold-exposure (Baseline: right $\mathrm{T}_{\mathrm{SCR}}$ mean difference: $0.04^{\circ} \mathrm{C}\left(95 \% \mathrm{Cl}-0.26\right.$ to $\left.0.34^{\circ} \mathrm{C}\right), \mathrm{p}=0.79$; left $\mathrm{T}_{\mathrm{SCR}}$ mean difference: $-0.07^{\circ} \mathrm{C}\left(95 \% \mathrm{Cl}-0.38\right.$ to $\left.0.23^{\circ} \mathrm{C}\right), \mathrm{p}=0.63$; Following cold-exposure: right $\mathrm{T}_{\mathrm{SCR}}$ mean difference: $0.01^{\circ} \mathrm{C}\left(95 \% \mathrm{Cl}-0.27\right.$ to $\left.0.29^{\circ} \mathrm{C}\right), \mathrm{p}=0.93$; left $\mathrm{T}_{\mathrm{SCR}}$ mean difference: $-0.01^{\circ} \mathrm{C}\left(95 \% \mathrm{Cl}-0.31\right.$ to $\left.\left.0.29^{\circ} \mathrm{C}\right), \mathrm{p}=0.96\right)$.

\section{Discussion}

We found a sexual dimorphism in the skin temperature overlying supraclavicular BAT in young children which may be related to dietary intake. Boys exhibit higher BAT activity under resting and cold-stimulated conditions than girls of a similar age and BMI, indicating that boys may have not only higher basal BAT activity under free-living conditions but also BAT that is more responsive to cold stimulation.

Previous investigations of the impact of sex on BAT in healthy young children are currently limited, with the majority of studies confined to clinical imaging in the context of paediatric malignancy. Furthermore, as the purpose of such scanning is to determine disease recurrence/progression, these scans are undertaken under environmental conditions designed to minimise BAT uptake of radio-labelled FDG (i.e. warm room temperatures) and do not measure BAT activity in response to physiological BAT substrates. Despite these limitations a small number of studies support our findings. Gilsanz et al found no sex-specific differences in the numbers defined as BAT positive on PET-CT ( $57 \%$ girls vs $60 \%$ boys), however multiple regression analysis identified an independent effect of sex on BAT volume after adjustment for pubertal stage, BMI, season and exposure to previous glucocorticoid treatment ${ }^{14}$. Chalfant et al identified BAT in $65 \%$ of boys 
and only $50 \%$ of girls (using PET-CT following successfully treated malignancy) and, although not statistically significant, their study was not specifically powered to explore sex-differences ${ }^{27}$.

Similarly, Drubach et al reported no difference in overall BAT activity in boys and girls on PET-CT. However, when stratified by age group, median BAT activity was 2.4 times higher in boys than girls aged between 11 and 13 years ${ }^{26}$. Deng et al identified sex as a significant covariate of the MRI properties of BAT in 28 young healthy children aged 9-15 years, reporting increased markers of tissue perfusion (ADC - apparent tissue diffusion coefficient and $\mathrm{D}^{*}$ - perfusion coefficient) on diffusion-weighted imaging, and a higher $\mathrm{T} 2$ * using Dixon $\mathrm{MRI}^{25}$ findings, suggestive of higher BAT activity in boys in this age group. Even fewer studies have directly examined childhood BAT histologically, but those that have report either no sex-specific differences ${ }^{11}$, or did not look for them ${ }^{10,11}$.

Differences between pre-pubertal girls and boys which are contrary to our findings have been reported ${ }^{30}$. However, these differences were principally identified when "area" of the SCR $\left(A r e a_{S C R}\right)$ was used as a thermal index. This measure, defined as the number of pixels over an arbitrary threshold of $35.5^{\circ} \mathrm{C}$, has yet to be validated against other assessments of BAT, such as PET-CT in the same way as $\mathrm{T}_{\text {SCR. }}$.

The children taking part in this study were between the ages of 8.5 and 11.8 years. The UK median age of pubertal onset is $11.3^{38}$ and 11.6 years for girls and boys respectively, meaning our study population may be a heterogeneous group in terms of pubertal stage. It is, therefore, likely that they exhibited a wide range of gonadotrophin and sex steroid hormones which could explain, in part, variation in basal and cold-

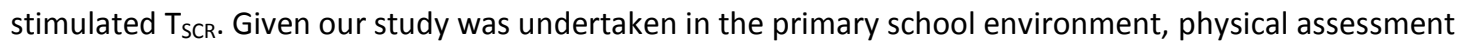
of pubertal stage was not considered appropriate. Future study under laboratory conditions utilising selfreported pubertal stage in combination with non-invasive measures of sex steroid hormones (e.g. saliva or urinary assays) presents a practical and ethical solution to the assessment of $T_{S C R}$ in relation to pubertal status for future studies.

Our univariate analyses suggest BAT thermogenesis may also be influenced by dietary intake in a sexspecific manner. In girls, higher vegetable and protein consumption was associated with a lower $\mathrm{T}_{\mathrm{SCR}}$ (lower 
BAT activity). However, the sample size of our study was limited and it was underpowered to detect significant relationships between $\mathrm{T}_{\mathrm{SCR}}$ and food consumption after correction for multiple testing. Parental reports of dietary intake may be subject to bias. Hours of screen time are commonly used as a simple assessment of sedentary behaviour ${ }^{39}$ but may falsely classify some children as active, and can also be associated with dietary intake ${ }^{40}$. The use of accelerometry in future studies could provide a comprehensive assessment of movement duration and intensity.

The insulative effect of overlying subcutaneous adipose tissue (SCAT) has not been quantified. Gatidis et al suggest SCAT significantly impacts $\mathrm{T}_{\mathrm{SCR}}$ however, their measurements were defined as the minimal distance between the vascular compartment and the skin of the neck ${ }^{41}$ (rather than the white fat layer that lies immediately below the dermis). Biopsy of adipose tissue surrounding the supraclavicular vasculature clearly demonstrates $\mathrm{UCP} 1^{42}$ indicative of capacity for thermogenesis. Therefore, the assumption that this layer is purely insulative is too simplistic. As the white fat layer immediately below the skin in the posterior triangle of the skin is minimal in healthy subjects in our studies we have been unable to obtain reproducible and robust measures with either ultrasound or magnetic resonance imaging. We have however identified that the relationship between $\mathrm{T}_{\mathrm{SCR}}$ and $\mathrm{BMI}$ persists in a non-obese group following adjustment for SCAT in close proximity to the SCR (dorsal aspect at T1) (unpublished data). The dynamic response of $\mathrm{T}_{\mathrm{SCR}}$ correlates well with FDG uptake in BAT on PET-CT in a non-obese adult cohort with proven FDG detected $\mathrm{BAT}^{15}$, the children in this study were similarly non-obese, and all had a BMI centile of $\leq 85^{\text {th }}$ centile. These findings suggest that the insulative effect of SCAT is minimal, in a non-obese population at least.

Given the contribution of BAT to energy balance and metabolic health, further exploration of these findings will provide a better understanding of how BAT may be activated, and recruited, in early life. This helps to delineate how BAT dysfunction may predispose to childhood obesity.

\section{Acknowledgements}


The Authors wish to thank the parents and children and schools for participating in this study, Taoli Zhang for data collection, and Richard Ridgwell for administrative support, Taoli Zhang was employed and funded by the University Of Nottingham School Of Psychology, and Richard Ridgwell provided his free-lance administrative services for free, there are no conflicts of interest for either party.

\section{Figures and Tables}

Table 1. Demographic and anthropometric variables in healthy girls and boys aged 8-11 years $(n=36)$. *Contaminated by socially desirable responding; ${ }^{*}$ Food consumption score: higher numerical value = lower consumption

Figure-1. Change in supraclavicular skin temperature following 5 minutes single hand immersion in cool water. A) representative anterior thermal images of a girl and boy (matched for age and BMI centile) at baseline and following cold exposure and B) left sided change in supraclavicular temperature following 5 minutes cold exposure in healthy girls and boys aged 8-11 years $(n=36)$. Post-hoc pair-wise comparisons Right $\mathrm{T}_{\mathrm{SCR}}: F(1,15)=11.38, \mathrm{p}=0.004$, partial $\eta^{2}=0.43$; left $\mathrm{T}_{\mathrm{SCR}}: F(1,15)=15.16, \mathrm{p}=0.007$, partial $\eta^{2}=0.50, * \mathrm{P}$ $<0.05$.

Table 2 Unadjusted means (SEM) for left and right supraclavicular skin temperatures ( $T_{S C R}$ ) and means (SEM) adjusted for BMI percentile ${ }^{¥}$ in healthy girls and boys prior to, and following, 5 minutes coldexposure (n=36). ${ }^{\ddagger}$ ANCOVA, BMI percentile; ${ }^{*} \mathrm{P}<0.05$, boys compared to-with girls; ${ }^{\$} \mathrm{P}<0.05$, left compared to-with right; ${ }^{\mathrm{P}}<0.05$, baseline compared to-with cold-exposed.

Table 3. Relationship between supraclavicular skin temperature $\left(T_{S C R}\right)$ measured by infrared thermography and food consumption score in healthy volunteer boys and girls aged 8-11 years ( $n=36)$. Pearson's $r, 95 \%$ confidence intervals, $\mathrm{R} 2$ and $\mathrm{p}$ value. ${ }^{*} \mathrm{P}<0.05$; bold type indicates statistical significance following adjustment for multiple comparisons. 
Table 4 online. Means (SEM) for left and right supraclavicular skin temperature $\left(T_{\text {SCR }}\right)$, unadjusted and adjusted for BMI percentile, in sedentary and active healthy children at baseline, and following 5 minutes cold-exposure $(n=36)$. (ANCOVA: baseline left $T_{S C R} F=0.25$, partial $\eta^{2}=0.008, p=0.62$, right $T_{S C R} F=1.66$, partial $\eta^{2}=0.051, p=0.28$; cold stimulated left $T_{S C R} F=0.04$, partial $\eta^{2}=0.001, p=0.84$ cold stimulated right $T_{S C R}$ $F=0.06$, partial $\left.\eta^{2}=0.002, p=0.81\right)$.

Table 5 online. Means (SEM) for the left and right supraclavicular skin temperature, unadjusted and adjusted for BMI percentile, in children classified as picky or non-picky eaters at baseline and following 5 minutes cold-exposure ( $n=36)$. (ANCOVA: baseline left $T_{S C R} F=0.11$, partial $\eta^{2}=0.004, p=0.77$, right $T_{S C R}$ $F=0.01$, partial $\eta^{2}=0.0004, p=0.92$; cold stimulated left $T_{S C R} F=0.12$, partial $\eta^{2}=0.004, p=0.73$, cold stimulated right $T_{S C R} F=0.13$, partial $\eta^{2}=0.004, p=0.72$ ).

\section{References}

[1] Ncd-Risk-Factor-Collaboration, Bentham J, Di Cesare M, Bilano V, Bixby H, Zhou B, et al. Worldwide trends in body-mass index, underweight, overweight, and obesity from 1975 to 2016: a pooled analysis of 2416 population-based measurement studies in 128.9 million children, adolescents, and adults. The Lancet. 2017;390:2627-42.

[2] Tirosh A, Shai I, Afek A, Dubnov-Raz G, Ayalon N, Gordon B, et al. Adolescent BMI trajectory and risk of diabetes versus coronary disease. The New England Journal of Medicine. 2011;364:1315-25.

[3] Eriksson JG, Forsén T, Tuomilehto J, Osmond C, Barker DJP. Early adiposity rebound in childhood and risk of Type 2 diabetes in adult life. Clinical and Experimental Diabetes and Metabolism. 2003;46:190-4.

[4] Saito M. Brown Adipose Tissue as a Regulator of Energy Expenditure and Body Fat in Humans. Diabetes \& Metabolism Journal. 2013;37:22-9.

[5] Carpentier AC, Blondin DP, Virtanen KA, Richard D, Haman F, Turcotte ÉE. Brown Adipose Tissue Energy Metabolism in Humans. Frontiers in Endocrinology. 2018;9:1-21.

[6] Chondronikola M, Volpi E, Børsheim E, Porter C, Saraf MK, Annamalai P, et al. Brown Adipose Tissue Activation Is Linked to Distinct Systemic Effects on Lipid Metabolism in Humans. Cell Metabolism. 2016;23:1200-6.

[7] Zingaretti MC, Crosta F, Vitali A, Guerrieri M, Frontini A, Cannon B, et al. The presence of UCP1 demonstrates that metabolically active adipose tissue in the neck of adult humans truly represents brown adipose tissue. The FASEB Journal. 2009;23:3113-20.

[8] Heaton JM. The distribution of brown adipose tissue in the human. Journal of Anatomy. $1972 ; 112: 35-9$.

[9] Lean M, James W, Jennings G, Trayhurn P. Brown adipose tissue uncoupling protein content in human infants, children and adults. Clinical Science (London). 1986;71:291-7.

[10] Ojha S, Fainberg HP, Wilson V, Pelella G, Castellanos M, May S, et al. Gene pathway development in human epicardial adipose tissue during early life. JCI Insight. 2016;1:e87460.

[11] Rockstroh D, Landgraf K, Wagner IV, Gesing J, Tauscher R, Lakowa N, et al. Direct evidence of brown adipocytes in different fat depots in children. PLoS ONE. 2015;10:e0117841.

[12] Virtanen KA, Lidell ME, Orava J, Heglind M, Westergren R, Niemi T, et al. Functional brown adipose tissue in healthy adults. The New England Journal of Medicine. 2009;360:1518-25.

[13] Blood cholesterol and vascular mortality by age, sex, and blood pressure: a meta- analysis of individual data from 61 prospective studies with 55000 vascular deaths. The Lancet. 2007;370:182939.

[14] Gilsanz V, Smith ML, Goodarzian F, Kim M, Wren TAL, Hu HH. Changes in Brown Adipose Tissue in Boys and Girls during Childhood and Puberty. The Journal of Pediatrics. 2012;160:604-9.e1. 
[15] Law J, Morris DE, Izzi Engbeaya C, Salem V, Coello C, Robinson LJ, et al. Thermal imaging is a non-invasive alternative to PET-CT for measurement of brown adipose tissue activity in humans. Journal of Nuclear Medicine. 2018;59:516-22.

[16] Jang C, Jalapu S, Thuzar M, Law PW, Jeavons S, Barclay JL, et al. Infrared thermography in the detection of brown adipose tissue in humans. Physiological Reports. 2014;2:1-7.

[17] Mariëtte RB, Leontine EHB, Rianne ADVDL, Lenka Pereira A-B, Frits S, Hein JV, et al.

Supraclavicular skin temperature as a measure of $18 \mathrm{~F}-\mathrm{FDG}$ uptake by BAT in human subjects. PLoS ONE. 2014;9:e98822.

[18] Bloor ID, Symonds ME. Sexual dimorphism in white and brown adipose tissue with obesity and inflammation. Hormones and Behavior. 2014;66:95-103.

[19] Valencak TG, Osterrieder A, Schulz TJ. Sex matters: The effects of biological sex on adipose tissue biology and energy metabolism. Redox Biology. 2017;12:806-13.

[20] Cypess AM, Lehman S, Williams G, Tal I, Rodman D, Goldfine AB, et al. Identification and importance of brown adipose tissue in adult humans. The New England Journal of Medicine. 2009;360:1509-17.

[21] Pfannenberg C, Werner MK, Ripkens S, Stef I, Deckert A, Schmadl M, et al. Impact of age on the relationships of brown adipose tissue with sex and adiposity in humans. Diabetes. 2010;59:1789-93.

[22] Ponrartana S, Aggabao PC, Hu HH, Aldrovandi GM, Wren TAL, Gilsanz V. Brown adipose tissue and its relationship to bone structure in pediatric patients. The Journal of Clinical Endocrinology and Metabolism. 2012;97:2693-8.

[23] Gilsanz V, Chung SA, Jackson H, Dorey FJ, Hu HH. Functional Brown Adipose Tissue is Related to Muscle Volume in Children and Adolescents. The Journal of Pediatrics. 2011;158:722-6.

[24] Zukotynski K, Fahey F, Laffin S, Davis R, Treves S, Grant F, et al. Constant ambient temperature of $24^{\circ} \mathrm{C}$ significantly reduces FDG uptake by brown adipose tissue in children scanned during the winter. European Journal of Nuclear Medicine and Molecular Imaging. 2009;36:602-6.

[25] Deng J, Schoeneman S, Zhang H, Kwon S, Rigsby C, Shore R, et al. MRI characterization of brown adipose tissue in obese and normal-weight children. Pediatric Radiology. 2015;45:1682-9.

[26] Drubach LA, Palmer EL, Connolly LP, Baker A, Zurakowski D, Cypess AM. Pediatric Brown Adipose Tissue: Detection, Epidemiology, and Differences from Adults. The Journal of Pediatrics. 2011;159:939-44.

[27] Chalfant JS, Smith $\mathrm{ML}, \mathrm{Hu} \mathrm{HH}$, Dorey FJ, Goodarzian F, $\mathrm{Fu} \mathrm{CH}$, et al. Inverse association between brown adipose tissue activation and white adipose tissue accumulation in successfully treated pediatric malignancy. The American journal of clinical nutrition. 2012;95:1144-9.

[28] Robinson L, Ojha S, Symonds ME, Budge H. Body Mass Index as a Determinant of Brown Adipose Tissue Function in Healthy Children. The Journal of Pediatrics. 2014;164:318-22.e1.

[29] Symonds ME, Henderson K, Elvidge L, Bosman C, Sharkey D, Perkins AC, et al. Thermal Imaging to Assess Age-Related Changes of Skin Temperature within the Supraclavicular Region Co-Locating with Brown Adipose Tissue in Healthy Children. The Journal of Pediatrics. 2012;161:892-8.

[30] Malpique R, Gallego-Escuredo JM, Sebastiani G, Villarroya J, López-Bermejo A, de Zegher F, et al. Brown adipose tissue in prepubertal children: associations with sex, birthweight, and metabolic profile. International Journal of Obesity. 2018.

[31] Scotney H, Symonds ME, Law J, Budge H, Sharkey D, Manolopoulos KN. Glucocorticoids modulate human brown adipose tissue thermogenesis in vivo. Metabolism. 2017;70:125-32.

[32] Wardle J, Sanderson S, Leigh Gibson E, Rapoport L. Factor-analytic structure of food preferences in four-year-old children in the UK. Appetite. 2001;37:217-23.

[33] Townsend E, Pitchford NJ. Baby knows best? The impact of weaning style on food preferences and body mass index in early childhood in a case-controlled sample. BMJ Open. 2012;2:.e000298.

[34] Nunnally JC. Psychometric theory. 2nd ed. ed. New York ; London: New York ; London : McGrawHill; 1978.

[35] Strahan R, Gerbasi K. Short, homogeneous versions of the Marlow-Crowne social desirability scale. Journal of Clinical Psychology. 1972;28:191-3.

[36] NHS. BMI Healthy Weight Calculator. 2015. p.

http://www.nhs.uk/Tools/Pages/Healthyweightcalculator.aspx.

[37] Benjamini Y, Yekutieli D. The Control of the False Discovery Rate in Multiple Testing under Dependency. The Annals of Statistics. 2001;29:1165-88.

[38] RCOG. Sex steroid treatment for pubertal induction and replacement in the adolescent girl: Scientific Impact paper no. 40. Scientific Impact Paper2013. p. 6.

[39] Pearson N, Biddle SJ. Sedentary behavior and dietary intake in children, adolescents, and adults. A systematic review. Am J Prev Med. 2011;41:178-88.

[40] Fletcher E, Leech R, McNaughton SA, Dunstan DW, Lacy KE, Salmon J. Is the relationship between sedentary behaviour and cardiometabolic health in adolescents independent of dietary intake? A systematic review. Obes Rev. 2015;16:795-805. 
[41] Gatidis S, Schmidt H, Pfannenberg CA, Nikolaou K, Schick F, Schwenzer NF. Is It Possible to Detect Activated Brown Adipose Tissue in Humans Using Single-Time-Point Infrared Thermography under Thermoneutral Conditions? Impact of BMI and Subcutaneous Adipose Tissue Thickness. PLoS One. 2016;11:e0151152.

[42] Lee JH, Kim JM, Choi MJ, Kang YE, Joung KH, Yi HS, et al. Clinical Implications of UCP1 mRNA Expression in Human Cervical Adipose Tissue Under Physiological Conditions. Obesity (Silver Spring). 2018;26:1008-16. 
Table 1.

\begin{tabular}{|c|c|c|c|}
\hline \multirow{2}{*}{ Variable } & \multicolumn{2}{|c|}{ Value } & \multirow[b]{2}{*}{$\begin{array}{c}P \\
\text { value }\end{array}$} \\
\hline & Boys $(n=16)$ & Girls(n=20) & \\
\hline Age (decimal years) & $9.9(0.24)$ & $8.5(0.23)$ & 0.62 \\
\hline Height $(\mathrm{cm})$ & $138.8(2.0)$ & $139.0(1.7)$ & 0.94 \\
\hline Weight (kg) & $31.81(1.33)$ & $34.89(1.72)$ & 0.12 \\
\hline BMI percentile & $48.36(8.00)$ & $59.57(6.63)$ & 0.28 \\
\hline Ambient temperature $\left({ }^{\circ} \mathrm{C}\right)$ & $22.01(0.20)$ & $22.10(0.14)$ & 0.71 \\
\hline $\mathrm{T}_{\mathrm{SCR}}$ pre cold exposure $\left({ }^{\circ} \mathrm{C}\right)$ & $36.02(-0.14)$ & $\begin{array}{c}35.63(- \\
0.12)\end{array}$ & 0.03 \\
\hline $\mathrm{T}_{\mathrm{SCR}}$ post cold exposure $\left({ }^{\circ} \mathrm{C}\right)$ & $36.17(-0.14)$ & $\begin{array}{c}35.62(- \\
0.12)\end{array}$ & 0.004 \\
\hline $\mathrm{T}_{\mathrm{mp}}$ pre cold exposure $\left({ }^{\circ} \mathrm{C}\right)$ & $32.96(-0.25)$ & $\begin{array}{c}33.13(- \\
0.31)\end{array}$ & 0.65 \\
\hline $\mathrm{T}_{\mathrm{mp}}$ post cold exposure $\left({ }^{\circ} \mathrm{C}\right)$ & $33.36(-0.22)$ & $\begin{array}{c}33.09(- \\
0.27) \\
\end{array}$ & 0.46 \\
\hline $\begin{array}{l}\text { Hand temperature drop }\left({ }^{\circ} \mathrm{C} \text {, }\right. \\
\mathrm{n}=28)(\mathrm{F}: \mathrm{n}=16 ; \mathrm{M}: \mathrm{n}=12)\end{array}$ & $-8.85(-0.30)$ & $-8.00(-0.57)$ & 0.20 \\
\hline TV watching (hrs) & $2.12(0.26)$ & $2.20(0.24)$ & 0.84 \\
\hline Picky eater (yes) & $8 / 16$ & $11 / 20$ & 0.76 \\
\hline \multicolumn{4}{|l|}{$\begin{array}{l}\text { Food consumption score } \\
\text { (Likert-item group sum) }^{\#}\end{array}$} \\
\hline Protein & $61.69(2.67)$ & $63.60(2.13)$ & 0.57 \\
\hline Vegetable & $84.94(4.66)$ & $86.45(2.85)$ & 0.77 \\
\hline
\end{tabular}

\# food consumption score: higher value = lower consumption

$\mathrm{T}_{\mathrm{SCR}}$ : supraclavicular skin temperature; $\mathrm{T}_{\mathrm{mp}}$ : mandibular prominence temperature 
Table 2.

\begin{tabular}{|c|c|c|c|c|c|c|c|}
\hline & & \multicolumn{6}{|c|}{ Supraclavicular skin temperature $\left({ }^{\circ} \mathrm{C}\right)$} \\
\hline & & \multicolumn{2}{|c|}{ Baseline } & \multicolumn{2}{|c|}{ Cold exposure } & \multicolumn{2}{|c|}{$\Delta T_{S C R}$} \\
\hline & & Boys & Girls & Boys & Girls & Boys & Girls \\
\hline \multirow{2}{*}{ 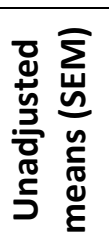 } & Left $T_{S C R}$ & $\begin{array}{c}35.88^{* \$} \\
(0.13)\end{array}$ & $\begin{array}{l}35.47^{\$} \\
(0.13)\end{array}$ & $\begin{array}{c}36.06^{* \$ \#} \\
(0.14)\end{array}$ & $\begin{array}{l}35.51^{\$} \\
(0.13)\end{array}$ & $\begin{array}{l}0.18^{* \$} \\
(0.05)\end{array}$ & $\begin{array}{c}0.03^{\$} \\
(0.04)\end{array}$ \\
\hline & Right $\mathrm{T}_{\mathrm{SCR}}$ & $\begin{array}{l}36.02^{*} \\
(0.14)\end{array}$ & $\begin{array}{l}35.63 \\
(0.12)\end{array}$ & $\begin{array}{c}36.17^{* \#} \\
(0.14)\end{array}$ & $\begin{array}{l}35.62 \\
(0.12)\end{array}$ & $\begin{array}{l}0.15^{*} \\
(0.04)\end{array}$ & $\begin{array}{r}-0.002 \\
(0.04)\end{array}$ \\
\hline \multirow{2}{*}{ 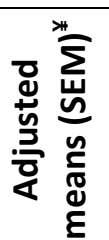 } & Left $T_{S C R}$ & $\begin{array}{l}35.81 \\
(0.11) \\
\end{array}$ & $\begin{array}{l}35.53 \\
(0.10) \\
\end{array}$ & $\begin{array}{l}35.98 \\
(0.11) \\
\end{array}$ & $\begin{array}{l}35.57 \\
(0.10) \\
\end{array}$ & $\begin{array}{c}0.17 \\
(0.04) \\
\end{array}$ & $\begin{array}{c}0.04 \\
(0.04) \\
\end{array}$ \\
\hline & Right $T_{S C R}$ & $\begin{array}{l}35.95 \\
(0.11)\end{array}$ & $\begin{array}{l}35.68 \\
(0.10)\end{array}$ & $\begin{array}{l}36.10 \\
(0.10)\end{array}$ & $\begin{array}{l}35.68 \\
(0.09)\end{array}$ & $\begin{array}{c}0.14 \\
(0.04)\end{array}$ & $\begin{array}{c}0.02 \\
(0.04)\end{array}$ \\
\hline
\end{tabular}


Table 3.

\begin{tabular}{|c|c|c|c|c|c|c|c|c|c|c|c|c|c|c|}
\hline & & & \multicolumn{6}{|c|}{ Boys } & \multicolumn{6}{|c|}{ Girls } \\
\hline & & & \multicolumn{3}{|c|}{ Left } & \multicolumn{3}{|c|}{ Right } & \multicolumn{3}{|c|}{ Left } & \multicolumn{3}{|c|}{ Right } \\
\hline & & & $\begin{array}{l}\text { Pre } \\
T_{S C R}\end{array}$ & $\begin{array}{c}\text { Post } \\
T_{\text {SCR }}\end{array}$ & $\Delta \mathrm{T}_{\mathrm{SCR}}$ & $\begin{array}{l}\text { Pre } \\
\mathrm{T}_{\text {SCR }}\end{array}$ & $\begin{array}{c}\text { Post } \\
T_{S C R}\end{array}$ & $\Delta T_{S C R}$ & $\begin{array}{l}\text { Pre } \\
T_{S C R}\end{array}$ & $\begin{array}{l}\text { Post } \\
T_{S C R}\end{array}$ & $\Delta T_{S C R}$ & $\begin{array}{l}\text { Pre } \\
T_{S C R}\end{array}$ & $\begin{array}{c}\text { Post } \\
T_{\text {SCR }}\end{array}$ & $\Delta T_{S C R}$ \\
\hline \multirow{7}{*}{ 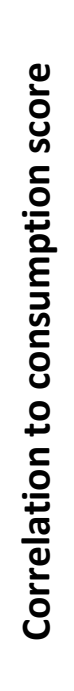 } & \multirow{7}{*}{ 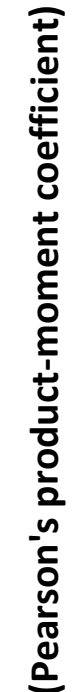 } & Carbohydrate & -0.05 & -0.02 & 0.10 & -0.09 & -0.09 & 0.00 & 0.21 & 0.16 & -0.19 & 0.20 & 0.20 & 0.01 \\
\hline & & Dairy & -0.23 & -0.25 & -0.09 & -0.29 & -0.31 & -0.04 & 0.11 & 0.13 & 0.06 & 0.09 & 0.16 & 0.19 \\
\hline & & Fruit & -0.33 & -0.25 & 0.21 & -0.25 & -0.26 & -0.01 & -0.07 & -0.07 & 0.00 & -0.09 & -0.08 & 0.03 \\
\hline & & Protein & -0.02 & -0.08 & -0.19 & 0.07 & -0.03 & -0.31 & $0.48 *$ & $0.48^{*}$ & 0.00 & $0.47^{*}$ & $0.51^{*}$ & 0.09 \\
\hline & & Savoury & -0.19 & -0.26 & -0.23 & -0.20 & -0.27 & -0.24 & 0.32 & 0.28 & -0.12 & 0.39 & 0.39 & -0.01 \\
\hline & & Sweet & -0.39 & -0.42 & -0.12 & -0.43 & -0.46 & -0.07 & -0.19 & -0.15 & 0.13 & -0.12 & -0.08 & 0.14 \\
\hline & & Vegetable & 0.11 & 0.13 & 0.06 & -0.01 & 0.03 & 0.14 & $0.53^{*}$ & $0.46^{*}$ & -0.23 & $0.52 *$ & $0.48^{*}$ & -0.13 \\
\hline
\end{tabular}


Table 4.

\begin{tabular}{|c|c|c|c|c|c|c|c|c|c|}
\hline & & \multicolumn{4}{|c|}{ Left $\mathrm{T}_{\mathrm{SCR}}\left({ }^{\circ} \mathrm{C}\right)$} & \multicolumn{4}{|c|}{ Right $\mathrm{T}_{\mathrm{SCR}}\left({ }^{\circ} \mathrm{C}\right)$} \\
\hline & & \multicolumn{2}{|c|}{ Boys } & \multicolumn{2}{|c|}{ Girls } & \multicolumn{2}{|c|}{ Boys } & \multicolumn{2}{|c|}{ Girls } \\
\hline & & $\begin{array}{c}\text { Sedentary } \\
(n=10)\end{array}$ & $\begin{array}{c}\text { Active } \\
(n=6)\end{array}$ & $\begin{array}{c}\text { Sedentary } \\
(n=12)\end{array}$ & $\begin{array}{c}\text { Active } \\
(n=8)\end{array}$ & $\begin{array}{c}\text { Sedentary } \\
(n=10)\end{array}$ & $\begin{array}{c}\text { Active } \\
(n=6)\end{array}$ & $\begin{array}{c}\text { Sedentary } \\
(n=12)\end{array}$ & $\begin{array}{l}\text { Active } \\
(n=8)\end{array}$ \\
\hline \multirow{4}{*}{ 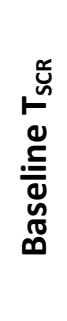 } & Mean & 35.82 & 35.97 & 35.50 & 35.44 & 35.88 & 36.26 & 35.64 & 35.60 \\
\hline & SE & 0.20 & 0.11 & 0.20 & 0.13 & 0.20 & 0.11 & 0.17 & 0.18 \\
\hline & Mean adjusted & 35.73 & 35.93 & 35.51 & 35.56 & 35.79 & 36.22 & 35.66 & 35.72 \\
\hline & SE & 0.14 & 0.18 & 0.13 & 0.16 & 0.13 & 0.17 & 0.12 & 0.15 \\
\hline \multirow{4}{*}{ 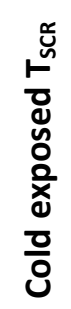 } & Mean & 36.06 & 36.06 & 35.51 & 35.51 & 36.11 & 36.27 & 35.61 & 35.65 \\
\hline & SE & 0.22 & 0.09 & 0.20 & 0.13 & 0.22 & 0.08 & 0.17 & 0.16 \\
\hline & Mean adjusted & 35.96 & 36.01 & 35.53 & 35.64 & 36.01 & 36.23 & 35.63 & 35.78 \\
\hline & SE & 0.14 & 0.18 & 0.12 & 0.15 & 0.13 & 0.16 & 0.11 & 0.14 \\
\hline
\end{tabular}


Table 5.

\begin{tabular}{|c|c|c|c|c|c|c|c|c|c|}
\hline & & \multicolumn{4}{|c|}{ Left $\mathrm{T}_{\mathrm{SCR}}\left({ }^{\circ} \mathrm{C}\right)$} & \multicolumn{4}{|c|}{ Right $\mathrm{T}_{S C R}\left({ }^{\circ} \mathrm{C}\right)$} \\
\hline & & \multicolumn{2}{|c|}{ Boys } & \multicolumn{2}{|c|}{ Girls } & \multicolumn{2}{|c|}{ Boys } & \multicolumn{2}{|c|}{ Girls } \\
\hline & & $\begin{array}{l}\text { Picky } \\
(n=8)\end{array}$ & $\begin{array}{l}\text { Not picky } \\
\quad(n=8)\end{array}$ & $\begin{array}{c}\text { Picky } \\
(n=11)\end{array}$ & $\begin{array}{c}\text { Not picky } \\
(n=9)\end{array}$ & $\begin{array}{l}\text { Picky } \\
(n=8)\end{array}$ & $\begin{array}{l}\text { Not picky } \\
\quad(n=8)\end{array}$ & $\begin{array}{l}\text { Picky } \\
\text { (n=11) }\end{array}$ & $\begin{array}{c}\text { Not picky } \\
(n=9)\end{array}$ \\
\hline \multirow{4}{*}{ 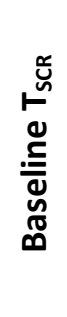 } & Mean & 35.96 & 35.79 & 35.49 & 35.46 & 36.07 & 35.98 & 35.57 & 35.69 \\
\hline & SE & 0.19 & 0.19 & 0.16 & 0.20 & 0.22 & 0.18 & 0.17 & 0.17 \\
\hline & Mean adjusted & 35.82 & 35.80 & 35.59 & 35.46 & 35.93 & 35.98 & 35.67 & 35.70 \\
\hline & SE & 0.16 & 0.16 & 0.14 & 0.15 & 0.16 & 0.16 & 0.13 & 0.15 \\
\hline \multirow{4}{*}{ 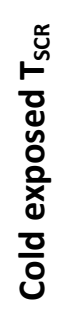 } & Mean & 36.12 & 36.00 & 35.49 & 35.53 & 36.27 & 36.07 & 35.55 & 35.71 \\
\hline & SE & 0.20 & 0.19 & 0.16 & 0.21 & 0.22 & 0.17 & 0.16 & 0.18 \\
\hline & Mean adjusted & 35.96 & 36.00 & 35.60 & 35.54 & 36.12 & 36.08 & 35.66 & 35.72 \\
\hline & SE & 0.16 & 0.15 & 0.13 & 0.14 & 0.15 & 0.14 & 0.12 & 0.14 \\
\hline
\end{tabular}


Figure

Click here to download high resolution image

A

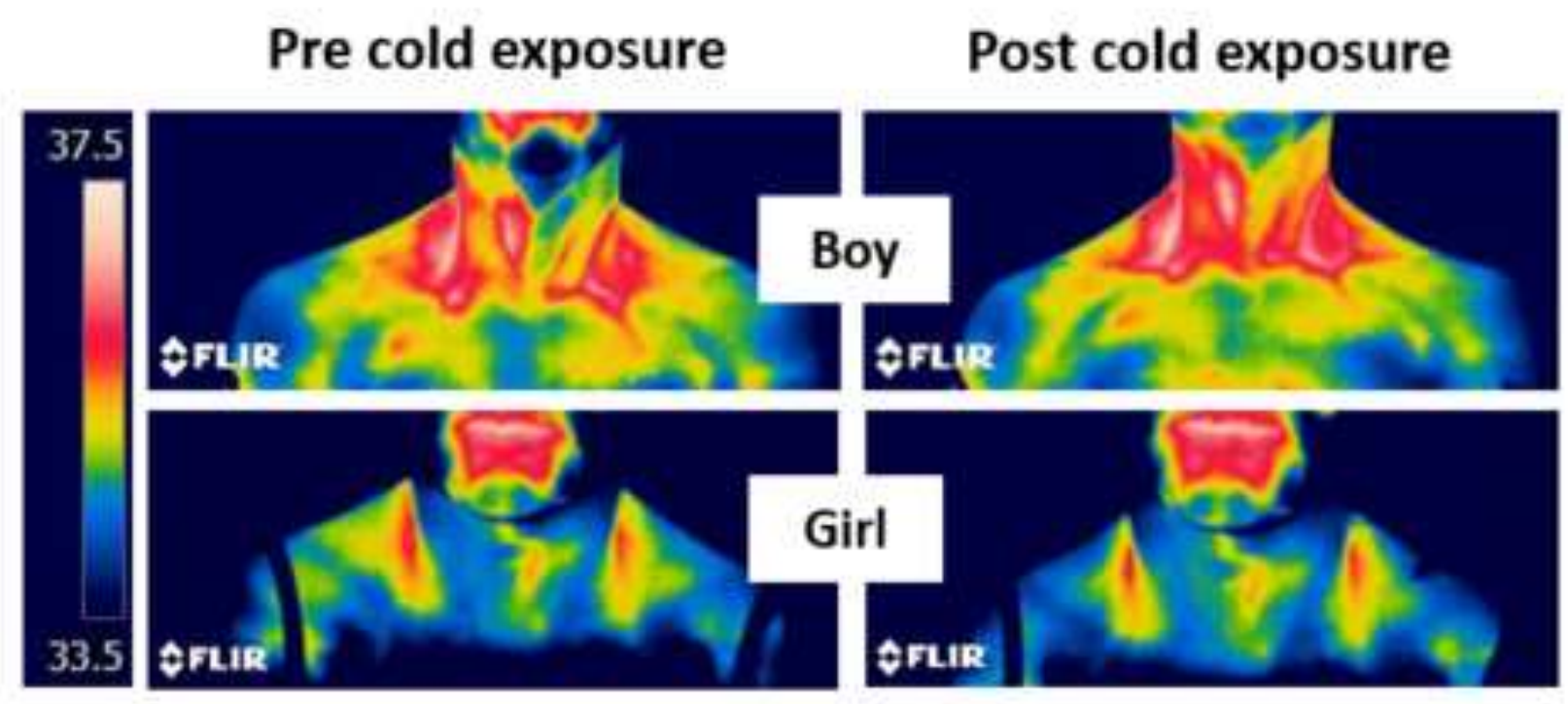

B

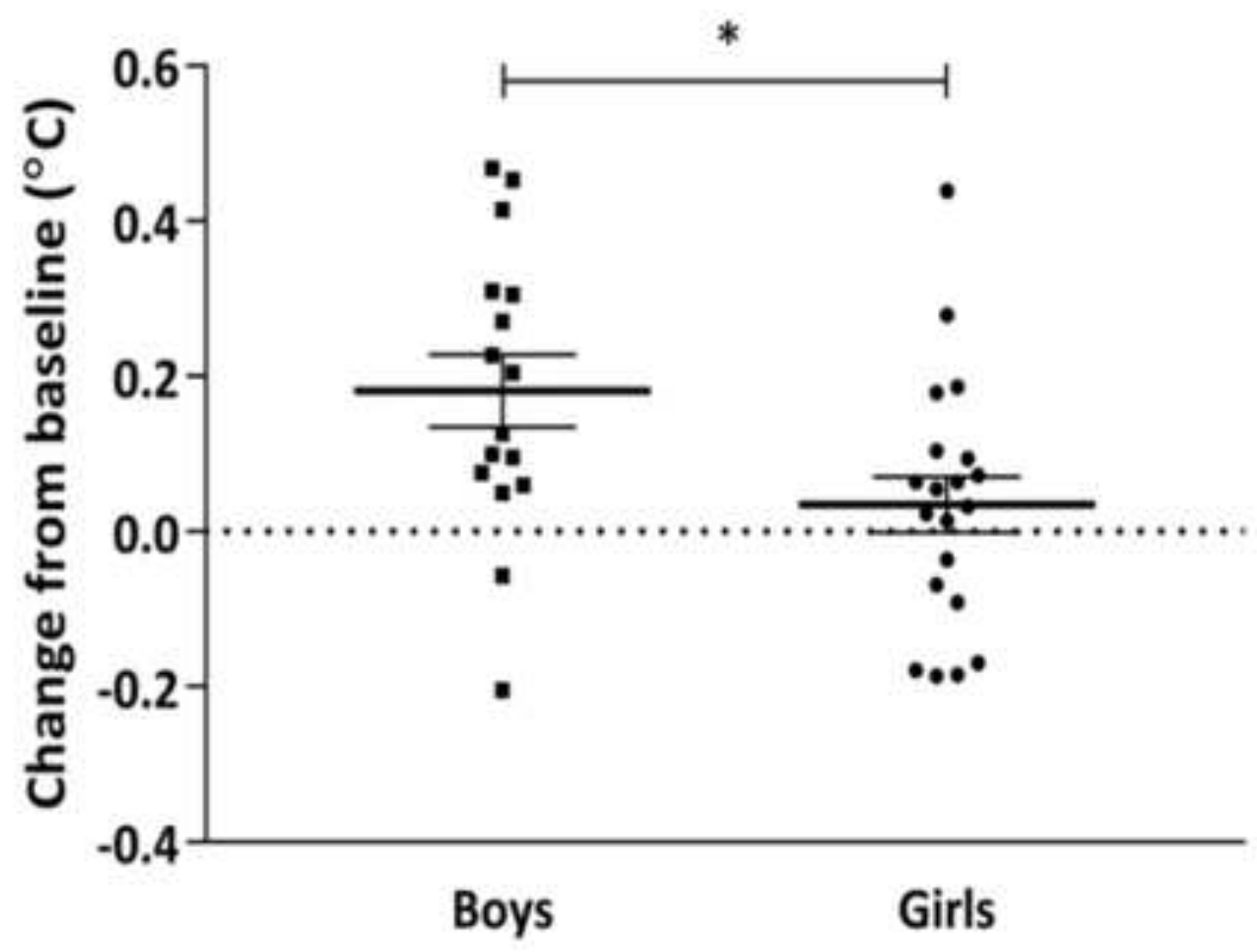




\section{Statistical analysis: online only content.}

\section{Two-way mixed ANOVA}

A two-way ANOVA was conducted to examine the effects of sex and coldexposure on $\mathrm{T}_{\mathrm{SCR}}$. Residual analysis was performed to test for the assumptions of the two-way ANOVA. Outliers were assessed by inspection of a box plot, normality was assessed using Shapiro-Wilk's normality test for each cell design and homogeneity of variances was assessed by Levene's test. There were no outliers, residuals were normally distributed $(P>0.05)$ and there was homogeneity of variances $(p>0.05)$.

\section{ANCOVA}

ANCOVA was performed to determine the effect of sex and cold-exposure on $\mathrm{T}_{\mathrm{SCR}}$ after controlling for BMI centile. There was a linear relationship between BMI centile and $\mathrm{T}_{\mathrm{SCR}}$ in girls and boys both at baseline and after cold-exposure, as assessed by visual inspection of a scatterplot. There were homogeneity of regression slopes as the interaction terms were not statistically significant. Standardised residuals for the sex , and for the overall model, were normally distributed, as assessed by Shapiro-Wilk's test $(p>0.05)$. There was homoscedasticity and homogeneity of variances, as assessed by visual inspection of a scatter plot and Levene's test of homogeneity of variance $(p>0.05)$, respectively. There were no outliers in the data, as shown by no cases with standardised residual greater than \pm 3 standard deviations. All assumptions for the multivariate analyses were met, except for the assumption for homogeneity of 
regression slopes - this was violated for the left and right $\Delta T_{S C R}$. Therefore, two-way ANCOVA was only undertaken for values of baseline and cold-exposed $\mathrm{T}_{\mathrm{SCR}}$.

\section{Two-way ANCOVA}

A two-way ANCOVA was conducted to examine the effects of sex and inactivity, and sex and eating behaviour on $\mathrm{T}_{\mathrm{SCR}}$ (after controlling for BMI centile). There was a linear relationship between BMI centile and TSCR for each group, as assessed by visual inspection of scatter plots. There was homogeneity of regression slopes as determined by comparison between the two-way ANCOVA models with, and without, interaction terms. There was homoscedasticity within groups, as assessed by visual inspection of the studentised residuals plotted against the predicted values for each group, and there was homogeneity of variances, as assessed by Levene's test of homogeneity of variance $(p>0.05)$. There were no outliers in the data, as shown by no cases with studentised residuals greater than \pm 3 standard deviations. There were no leverage or influential points, as assessed by leverage values and Cook's distance, respectively. Studentised residuals were normally distributed, as assessed by ShapiroWilk's test $(p>0.05)$.

The assumption for homogeneity of regression slopes was violated for the left and right $\Delta \mathrm{T}_{\mathrm{SCR}}$. Therefore, two-way ANCOVA was only undertaken for values of baseline and cold-exposed $T_{S C R}$. 
As summed food consumption scores were obtained using an 8-level item scale, and food groups consisted of more than 9 items, this was treated as continuous interval data. Pearson's product-moment correlation coefficients $(r)$ were calculated to determine the size of linear relationships between two variables (e.g. food consumption score and baseline $\left.T_{S C R}\right)$. 
STROBE Statement - Checklist of items that should be included in reports of cohort studies

\begin{tabular}{lcl|l} 
& $\begin{array}{c}\text { Item } \\
\text { No }\end{array}$ & \multicolumn{2}{c}{ Recommendation } \\
\hline Title and abstract & 1 & $\begin{array}{l}\text { (a) Indicate the study's design with a commonly used term in the title or the } \\
\text { abstract }\end{array}$ & 1,4 \\
& $\begin{array}{l}\text { (b) Provide in the abstract an informative and balanced summary of what } \\
\text { was done and what was found }\end{array}$ & 4 \\
\hline
\end{tabular}

\begin{tabular}{|c|c|c|c|}
\hline \multicolumn{4}{|l|}{ Introduction } \\
\hline Background/rationale & 2 & $\begin{array}{l}\text { Explain the scientific background and rationale for the investigation being } \\
\text { reported }\end{array}$ & $5-7$ \\
\hline Objectives & 3 & State specific objectives, including any prespecified hypotheses & $6-7$ \\
\hline \multicolumn{4}{|l|}{ Methods } \\
\hline Study design & 4 & Present key elements of study design early in the paper & 7 \\
\hline Setting & 5 & $\begin{array}{l}\text { Describe the setting, locations, and relevant dates, including periods of } \\
\text { recruitment, exposure, follow-up, and data collection }\end{array}$ & 7 \\
\hline Participants & 6 & $\begin{array}{l}\text { (a) Give the eligibility criteria, and the sources and methods of selection of } \\
\text { participants. Describe methods of follow-up } \\
\text { (b) For matched studies, give matching criteria and number of exposed and } \\
\text { unexposed }\end{array}$ & na \\
\hline Variables & 7 & $\begin{array}{l}\text { Clearly define all outcomes, exposures, predictors, potential confounders, } \\
\text { and effect modifiers. Give diagnostic criteria, if applicable }\end{array}$ & $7-10$ \\
\hline $\begin{array}{l}\text { Data sources/ } \\
\text { measurement }\end{array}$ & $8^{*}$ & $\begin{array}{l}\text { For each variable of interest, give sources of data and details of methods of } \\
\text { assessment (measurement). Describe comparability of assessment methods if } \\
\text { there is more than one group }\end{array}$ & $7-10$ \\
\hline Bias & 9 & Describe any efforts to address potential sources of bias & $8,13-15$ \\
\hline Study size & 10 & Explain how the study size was arrived at & 10 \\
\hline Quantitative variables & 11 & $\begin{array}{l}\text { Explain how quantitative variables were handled in the analyses. If } \\
\text { applicable, describe which groupings were chosen and why }\end{array}$ & $\begin{array}{l}10+ \\
\text { Appendix }\end{array}$ \\
\hline Statistical methods & 12 & 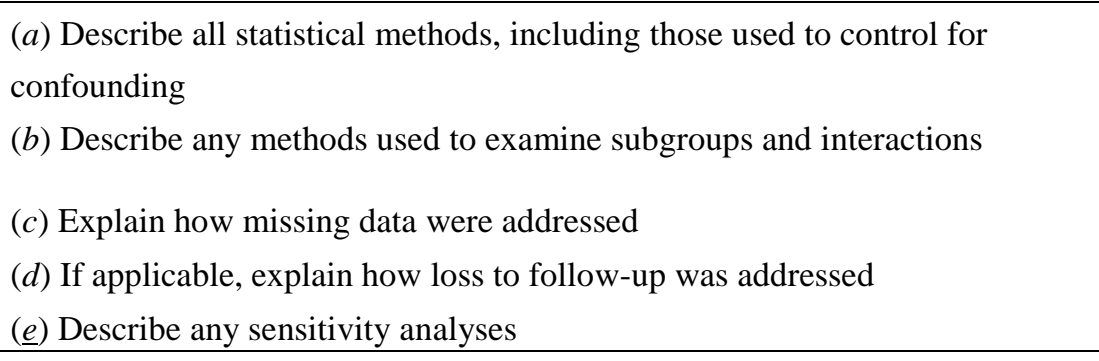 & $\begin{array}{l}10 \\
\text { appendix } \\
10 \\
\text { appendix } \\
\text { na } \\
\text { na } \\
\text { na }\end{array}$ \\
\hline \multicolumn{4}{|l|}{ Results } \\
\hline Participants & $13 *$ & $\begin{array}{l}\text { (a) Report numbers of individuals at each stage of study-eg numbers } \\
\text { potentially eligible, examined for eligibility, confirmed eligible, included in } \\
\text { the study, completing follow-up, and analysed } \\
\text { (b) Give reasons for non-participation at each stage } \\
\text { (c) Consider use of a flow diagram }\end{array}$ & $\begin{array}{l}\text { na } \\
\text { na }\end{array}$ \\
\hline Descriptive data & $14 *$ & $\begin{array}{l}\text { (a) Give characteristics of study participants (eg demographic, clinical, } \\
\text { social) and information on exposures and potential confounders } \\
\text { (b) Indicate number of participants with missing data for each variable of } \\
\text { interest } \\
\text { (c) Summarise follow-up time (eg, average and total amount) }\end{array}$ & $\begin{array}{l}\text { Table } 1 \\
\text { na } \\
7\end{array}$ \\
\hline Outcome data & $15^{*}$ & Report numbers of outcome events or summary measures over time & $\begin{array}{l}10-11+ \\
\text { Tables 1- }\end{array}$ \\
\hline
\end{tabular}




\begin{tabular}{|c|c|c|c|}
\hline Main results & 16 & $\begin{array}{l}\text { (a) Give unadjusted estimates and, if applicable, confounder-adjusted estimates and their } \\
\text { precision (eg, 95\% confidence interval). Make clear which confounders were adjusted for } \\
\text { and why they were included } \\
\text { (b) Report category boundaries when continuous variables were categorized }\end{array}$ & $\begin{array}{l}10-11 \\
+ \\
\text { Tables } \\
1-3 \\
\text { and } \\
\text { Fig } 1 \\
\text { na }\end{array}$ \\
\hline Other analyses & 17 & $\begin{array}{l}\text { Report other analyses done - eg analyses of subgroups and interactions, and sensitivity } \\
\text { analyses }\end{array}$ & na \\
\hline \multicolumn{4}{|l|}{ Discussion } \\
\hline Key results & 18 & Summarise key results with reference to study objectives & 12 \\
\hline Limitations & 19 & $\begin{array}{l}\text { Discuss limitations of the study, taking into account sources of potential bias or } \\
\text { imprecision. Discuss both direction and magnitude of any potential bias }\end{array}$ & 13,15 \\
\hline Interpretation & 20 & $\begin{array}{l}\text { Give a cautious overall interpretation of results considering objectives, limitations, } \\
\text { multiplicity of analyses, results from similar studies, and other relevant evidence }\end{array}$ & 15 \\
\hline Generalisability & 21 & Discuss the generalisability (external validity) of the study results & 15 \\
\hline \multicolumn{4}{|c|}{ Other information } \\
\hline Funding & 22 & $\begin{array}{l}\text { Give the source of funding and the role of the funders for the present study and, if } \\
\text { applicable, for the original study on which the present article is based }\end{array}$ & 2 \\
\hline
\end{tabular}

*Give information separately for exposed and unexposed groups.

Note: An Explanation and Elaboration article discusses each checklist item and gives methodological background and published examples of transparent reporting. The STROBE checklist is best used in conjunction with this article (freely available on the Web sites of PLoS Medicine at http://www.plosmedicine.org/, Annals of Internal Medicine at http://www.annals.org/, and Epidemiology at http://www.epidem.com/). Information on the STROBE Initiative is available at http://www.strobe-statement.org. 